\title{
On Developing China's Third Party Payment
}

\author{
Yong Jin, Wei Song, Jingyi Zhang \\ School of Management, Hubei University of Technology, P.R.China, \\ 430068 \\ jy6509@163.com,jy6509@21cn.com
}

\begin{abstract}
The development of the third party payment, which enhances electronic commerce's development greatly, provides a secure, efficient, convenient and low-cost way to transfer funds between the seller and the buyer With fast development of electronic commerce and fierce competition in the third party payment market, the central bank of China sets about granting profession licenses to related companies. This paper theoretically analyses the third party payment's development situation, operation mode and operation feature, and then offers strategies to develop China's third party payment.
\end{abstract}

As a separate operating agency, the third party payment platform, acting as intermediation in the process of dealing under the supervision of banks and business management departments, provides secure guarantee and technological support to the two trading parties. The platform, also acting as witness and channel of the network transaction, offers abundant payment means and reliable service to customers decreases the possibility of fraudulent trade and relieves public worries on the security of network transaction.

The platform of third party payment was investment hotspot of the year 2005, which is called "on-line payment year". Due to relaxed qualification cognizance, small payment companies sprang up and the scale of platform increased by 100 percent a year. According to IReserach's investigation, the third party payment in 2004 is 2.3 billion RMB, while the number was more than 30 billion RMB in 2006 and with an expectation of 280 billion RMB in 2010.

It is said that the People's Bank of China sets about granting license to the third party payment companies which means 80 percent small ones will be eliminated, thus perfecting operation mode becomes the most important issue for this industry.

Please use the following format when citing this chapter:

Jin, Y., Song, W., Zhang, J., 2007, in IFIP Intemational Federation for Information Processing, Volume 251, Integration and Innovation Orient to F-Society Volume1, Wang, W. (Fds), (Boston: Springer), pp. 578-585. 


\section{Development situation of China third party payment}

The 21st century is an era of information with thorough development of computer and network technology, and EC stride ahead in this era. Meanwhile multitudinous information technology enterprises, venture investment companies, and production circulation enterprises involve in the field of EC. Realized high growth of $73.7 \%$ in 2004 , the EC market paced into its steady growth stage since 2005, with a transaction sum 680 billion (increased by $41.7 \%$ ) and 1020 billion in 2006 (increased by $50 \%)$.

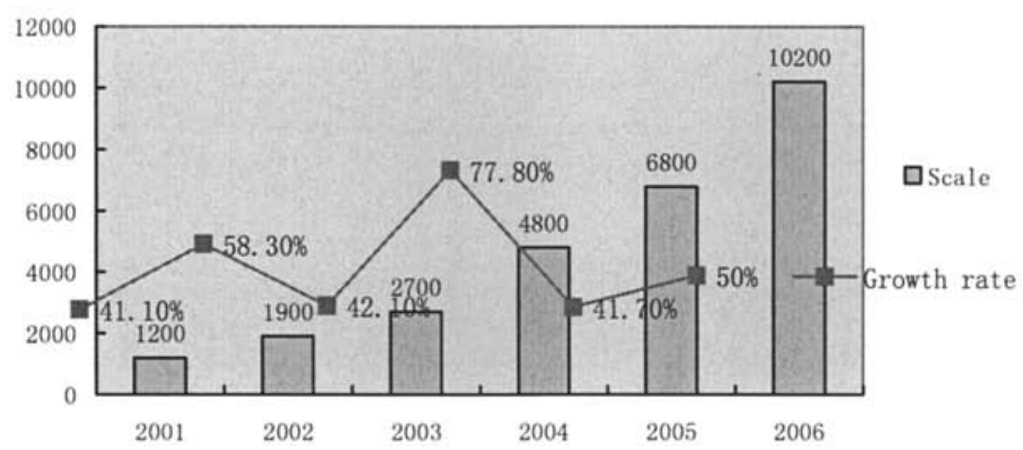

Fig. 1. Recent Development Tendency of China EC

Nowadays, two methods are widely used in the EC payment, one is electronic bank service and the other is the third party electronic payment service. According to the report of Ireserach, in China, $97 \%$ electronic payment is on-line payment, while only 3 percent is paid in form of mobile or telephone payment. All these prove that, in spite of the existence of immaturity and relaxed cooperation in this industrial chain, great achievement has been gained and on-line payment has been playing the most important role in the field of electronic payment. As to present case, on-line banks mainly deal with payments among enterprise (B2B), especially large and medium sized enterprises, whose sums of transacted money are large and their business partners are relatively stable, thus their interior ERP systems or self-constructed platforms are able to deal with the payments.

As for the domain of small-sum payments, such as B2C and C2C, services provided by single on-line bank could not satisfy the changing and flexible demands of smallsized customers. Similarly advanced technologies and costly maintenance expenses are beyond small-scaled network and business's management. Under such situation, the third party payment platform, a non-bank investment institution that is independent from both the payer and the payee, becomes a hot spot in the market of on-line payment. From 2001 to 2004, its annual compound growth rate is by 44.2 percent. By 2004, China's third party payment increased to 2.3 million RMB. 


\section{The Third Party's Payment Modes}

The third party's payment mode can roughly divided into two kinds: One acts as bank gateway proxy which provides many bank connections to the users; the other acts as transaction intermediary (whose main function is to bridge the buyer and the sell, and also connect the EC platform and the bank) to realize on-line fund transaction.

\subsection{The Mode of Payment Gateway}

From the whole process, the payment gateway mode can be regarded as a channel which links multi-banks and treaty-signed merchants, the buyer pays the seller indirectly through the third party payment platform and the third party provides compatible connection platform to the sellers.

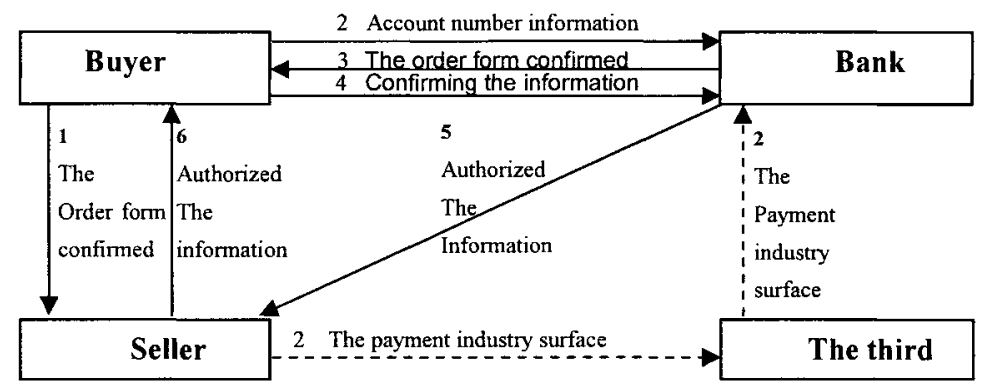

Fig. 2. Illustration of Payment Gateway Mode

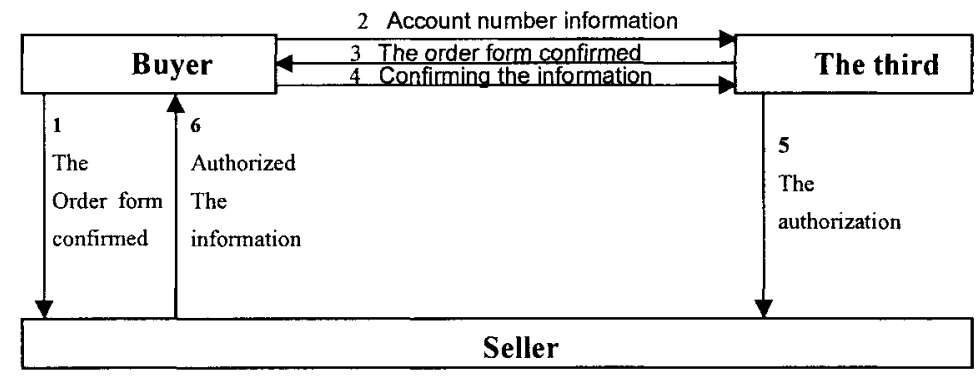

Fig. 3. Illustration of Credit Intermediary Mode

\section{2 The Mode of Credit Intermediary}

In order to increase two sides' credit, ensure well circulation to fund and cargo, the third party payment service, acting as the credit intermediary, arises at the historic moment, implements "receiving and paying on other's behaif " and "the credit 
guarantees". Once transaction intention arrived, the buyer will firstly deposited his money into the third party's, after receiving and checking his ordered good, the buyer informs the third party, then the third party will transfer the fund deposited in its payment platform to the seller account. In this mode, the third party actually acts as credit intermediary; deposits funds for two sides before the buyer claim their wanted good. So in certain degree, the credit intermediary mode is a byproduct of on-line transaction's "Credit vacancy".

\section{Operation Mode Analysis of the Third Party Payment}

At present, the third party payment companies, banks, merchants, exterior competitors have already constitutes a complex chain in the electronic payment industry. The relationship between the third party payment and bank's large-scale electronic interactive platform is extremely subtle because they mutually and closely dependent on each other. Analysis each part's relationship among such chain and its dependence degree to others, we may classify this operation mode, adopted by the third party payment operation, into two kinds:

\section{1 The Third Party's Gateway Operation Mode}

This mode refers to the value-added service operation platform provided by third party to signed customers and it is independent from electronic payment industry chain. Such operation businessman only provides operation platform for product payment and payment system, its front end provides kinds of payments for on-line merchants and on-line consumers, which correspondingly relates to the bank's electronic connection in rear end. While the third party payment operation businessman is responsible for transferring accounts among banks, and providing value-added services, such as order management and account inquiry. In China, both Payeasy and Pay 100 adopt this pattern.

This unique and flexible payment operation platform mainly faces B2B, B2C and G2C market, or provides payment settlement for small/medium-sized merchants and government-owned/private enterprises that are in need of payment. It's not consumers but banks and merchants (who are closely related to the third party operation business) who are users of the third party's gateway operation mode. This mode income mainly comes from bonus from banks' benefits, customers' annual expense and handling charge of transaction.

\section{2 The Third Party Payment Operation Mode Widened by EC Businessman}

\section{2 .1 Operation Mode Guaranteeing Payment Credit}

This mode is independently exploited by the large-scaled electronic transaction platform or cooperatively exploited with other investors. Relying on its financial strength and good public praise, operation businessman cooperates with banks, offers middle guarantee for the trading parties by the third party payment operation mode. Through electronic transaction platform and payment platform, the third party, acting 
as credit intermediary, does business with customers and guarantees transaction operation being carried out smoothly.

Owning integrate electronic transaction platform and abundant network customer resources, such kind payment operation businessman, facing to $\mathrm{C} 2 \mathrm{C}, \mathrm{B} 2 \mathrm{C}$ market, provides payment services to individuals and small/middle-sized business, plays the intermediary guarantee function, and establishes relatively reliable credit appraisal system for both sides according to the platform transaction recording. Its operating expense and benefit basically comes from network platform shop fee, commodity's landing fee, transaction service fee and so on. Nowadays popular domestic payments, such as Alipay, Paypal, Ebay and Tenpay, are using this operation mode.

\section{2 .2 Perfecting Payment Operation Mode Operated by EC Website}

This operation mode, refers to payment gateway established by EC website (platform) who deals with special product (hypothesized product or entity product). This mode, originated from existed payment and management platform serving for EC operation businessman's commodity delivery and payment, owns solid background, abundant capital and ready-made stable net-work user and the cloud-net pays@ net. It's a typical representative of such mode.

This type operation business originates from mature EC enterprise, so they are familiar with customers' payment demands and they target on B2C market and provide on-line payment service to middle/small-scaled EC website then obtain annual service charge as well as transaction handling charge as operation income.

\section{Prospective Analysis on the Third Party Payment}

For the lack of systemic supervision and management, disorderly competition exists in the field of third party payment business. Meanwhile, the banks (who the third party payment relies on), together with reduced foreign/domestic investment and negative effects produced by well-known EC websites, cause the third party payment enterprise's survival surrounding becoming worse and worse.

Under such background, the central bank of China sets about granting license to the third payment business in order to regularize this field. Regardless of whether it's easy or hard to gain this license, turbulence will arise in this profession and reform is unavoidable. After these, surviving enterprises are bound to partition the market, which leads to competition pattern, and then it's vital for the third party payment enterprise to prospect its development strategy. Several aspects should be taken into strategy design:

\section{1 Strengthening Theoretical Research, Enriching Operation Mode and Seeking Profit--making Points}

The third party does not involve in particular transaction, which guarantees information security, but its individual credit safeguard system can be popularized in $\mathrm{B} 2 \mathrm{~B}$ and $\mathrm{C} 2 \mathrm{C}$ transaction. On the other hand, $\mathrm{B} 2 \mathrm{~B}$ is rich in professions and each profession is characteristic and complicated, then sole and simple transaction or payment mode hinders B2B on-line payment's development. Consequently, while 
developing B2B on-line payment, the third party payment business must take profession difference into consideration, and intended acquaint it with particular profession demands. It should be aware of the key role of innovation, try hard to explore "value-added business". It's important for the third party to make good use of own resources superiority, localize its position accurately, divide market appropriately, and avoid homogeneity competition and unwise price war. It's equaled important to seek innovation spots from respects of business mode and product function, prominent good quality and well service of product, maintain and expands own superiority customer resources, and realize long-term stable development.

\section{2 Strengthening Governmental Supervision, Perfecting Monitoring System}

At present, China lacks of correlation law or policy to regularize network market, which leads to the third party payment profession is too relaxed and beyond any supervision. The third party payment platform appearing in the form of profit-earned but not public welfare organization is facing with possible risk in its operating process. Furthermore, because its service involves fund circulation, which possible leads to serious exterior negative effect. All those call for reasonable supervision and management to the third party payment.

The third party payment business acts intermediary just as what banks do in the international trade. But banks, as an important part of social economy body, own strong ability to resist risk and mature management laws and regulations and good credit. In order to develop itself appropriately, the third party payment profession has to win trust from the public and exploit its service smoothly, as well as avoid risk timely. All this prompts us that while resetting our confidence in the third party payment profession market, we should reelect our credits.

Although our country has enacted "Electronic Signature Law " and " the Electronic Payment Direction (First) ", but for its particular features, the third party payment service has not included in these laws. The administrative departments should try to fulfill the third party business development requirements, instruct and supervise its business. Supervising and managing organization department should be established to provide unitive services to the third party, evaluate its business, collect profession cases, balance the relationship among government administrative department, the profession terminal organization as well as customers, and enhance the third party's development. Only these can form a harmonious market, which is advantageous to the third party payment business development.

\subsection{Consummating Credit Safeguard System of On-line Payment System, Seeing} Secure Payment

For the existence of low threshold and supervising and managing system flaw, certain payment company has to take over some illegal transactions to make a living, this kind of case jeopardizes on-line payment's public image, produces negative effects on its long-term development and harm network payment security.

Driven by malignant competition and surviving pressure, most payment companies, so long as having trade (which are so limited) to do, concern themselves with 
transaction results, regardless of trade validity even though they are aware that many transactions are illegal money washing. Such continuous malignant competition withers the market and harms its harmonious development. It's well known that certain payment company provides a service (its maximum dealing amount is only several hundred Yuan.) which is nothing but providing operation convenience to wash illegal fund.

The existing weaknesses of the third party payment are partly due to the lack of network technology laws. The solutions to those problems lie in our whole society's efforts and the promotion of our overall qualities. Basing on service flow of the third party payment, administrative machinery and profession association should established fair and just evaluating system, regulate both sides' transaction behavior, establish credit appraisal organization for the third party, strengthen supervision and management to the transaction process. What's more, the EC profession itself should take care of these problems and promote the business's development by enhancing its immunity.

\subsection{Locating Market Position, Perfecting Payment Service}

On-line payment is an extension of finance industry network market, which should abide by corresponding national finance policy and rule. The third party payment industry should deepen its understanding to finance industry and EC, strengthen its service consciousness, cooperate with banks and obtain their financial guarantee, offer multiple terminal products and services to the users. All these contribute healthy development to the third party payment business.

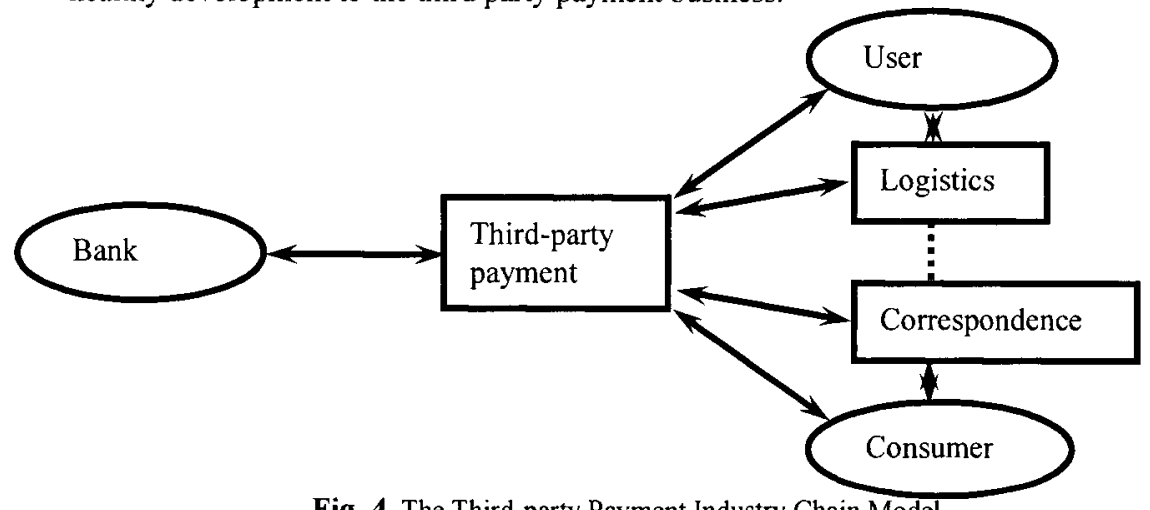

Fig. 4. The Third-party Payment Industry Chain Model

To enhance its profession competition ability, the third party payment enterprise should build and perfect its industrial chain, which is compatible with Internet and fulfilling electronic payment demand as to explore its value-added services. Based on development mode and capital background, the third party business must locate precisely its market position, identify its serving target, search for ways to stimulate its own development and satisfy customer various needs. At the same time, the third party business must build different managing pattern, enrich business concepts, perfect management structure and increase its payment pattern, carry out the plan of 
"vertical and horizontal alliance" in the field, rearrange professional resources, and enhance profession exterior competitive ability.

\subsection{Constructing Urban New Payment Network}

It's needed to construct the third party payment platform on the basis of urban synthetic safeguard system. This platform's front-end charge takes urban citizen (users of China telecom) as service terminal, its back-end charge takes urban nonprofit organizations as service terminal, which include local public utility payment (the charge of water, electricity, gas, cable TV), cultural and educational business payment (such as network education, test training, school jot charge) and civilization payment (including traveling admission ticket, net-line expense, traveling special product, hotel reservation, electronic airplane ticket, electronic theater-including online and electronic bill)

This concept is far from maturity, but it offers development direction for the third party payment. With the help of today's highly developed information technology, we are confident to change this imagination into reality.

\section{Summary}

In brief, the third party payment platform, compared with other existent of on-line payment, is superior in secure payment and reliable trading credit, especially in B2C and $\mathrm{C} 2 \mathrm{C}$. What's more, its jot payment solves effectively the "payment bottleneck" problem, which puzzles EC transaction for years. Today, the third party payment profession has already been attracting attentions from government, banks, payment companies as well as risk investor. There's not doubt that the third party payment service will continue to play important role in future EC activity. Along with the emergence of related rules, the third party payment profession tends to be more mature and more perfect.

\section{References}

1. H. Chen, Evaluating development of the third party payment platform [J] South China finance computer, 2007 (1)

2. J.Y. Zheng, Present situation, question and supervising and managing suggestion of the Third party on-line payment market [J]. Financial accountant, 2006 (7)

3. Y. Zhao, The third party payment pattern analysis and question exploration [D] Beijing: Capital normal university, 2006

4. E.L. Li, Analyzing research on the third party payment [D] Chengdu: Southwest Finance and Economics University, 2006

5. http:// www.iResearch.com 